\title{
Tarefas para Aulas Invertidas: relato de experiência docente com deveres de casa on-line em curso de Física ${ }^{+}$
}

Alexandre F. Faria ${ }^{l}$

Colégio Técnico - Universidade Federal de Minas Gerais

Arnaldo M. Vaz $^{1}$

Colégio Técnico

Programa de Pós-Graduação em Educação

Universidade Federal de Minas Gerais

Belo Horizonte - MG

\section{Resumo}

Tarefas para casa - ou deveres escolares - sempre estiveram presentes em Cursos de Física da Educação Básica e da Educação superior. As metodologias ativas atribuíram novas funções às lições de casa. Contudo, essas lições não têm sido objeto de pesquisa empírica, nem de relato docente. Neste relato de experiência, descrevemos o uso, em dois anos letivos, de tarefas on-line para sala de aula invertida junto a cinco turmas da $2^{a}$ série do Ensino Médio de uma escola pública federal localizada em Belo Horizonte. O relato inclui: precedentes dessa iniciativa; detalhes do contexto escolar; considerações reflexivoanalíticas; exemplo de desenvolvimento e implementação de uma tarefa; avaliação da iniciativa com base em taxas de resposta e de enquetes sobre as tarefas. Esta avaliação nos mostrou que, embora desinteressados pelos deveres escolares, os estudantes se engajaram na sua realização. Inferimos que seu engajamento decorre do trabalho da equipe de professores e da capacidade destes de convencer os estudantes da importância das tarefas para casa para o aprendizado em física.

Palavras-chave: Dever de Casa; Sala de Aula Invertida; Metodologias Ativas; Currículo; Ensino de Física.

\footnotetext{
${ }^{+}$Tasks for Flipped Classroom: teaching experience report with on-line homework in physics course

* Recebido: dezembro de 2019. Aceito: maio de 2020.

${ }^{1}$ E-mails: affaria@ufmg.br; arnaldovaz@ufmg.br
} 


\begin{abstract}
Homework has always been present in Physics Courses; both in highschool and higher education. Active methodologies gave it new functions. Despite this, home study have received little attention in empirical research papers or teacher's journal writing. In the present experience report, we describe the usage in two academic years of online homework for flipped classrooms with five 11th grade classes at a federal public school located in Belo Horizonte. The account includes: precedents for this initiative; the school context details; reflexiveanalytical considerations; instance of one homework's development and implementation; evaluation of the initiative based on response rates to homework and surveys about its acceptance. This evaluation showed us that, although uninterested in homework, the students were engaged in its accomplishment. We infer that their engagement stems from the work of the team of teachers and the ability of these to convince students of the importance of homework for learning physics.
\end{abstract}

Keywords: Homework; Flipped Classroom; Active Methodologies; Curriculum; Teaching of Physics.

\title{
I. Introdução
}

Apresentamos um relato de experiência sobre o desenvolvimento e a implementação de deveres de casa ${ }^{2}$ em um curso de física de nível médio cujas aulas são concebidas para classes invertidas. $\mathrm{O}$ conceito de classe invertida é relativamente novo, mas designa uma ideia que já circula há tempos no campo da Educação em Ciências (Cf. OLIVEIRA; ARAUJO; VEIT, 2016): as aulas devem ser espaço para a reflexão, o debate e a elaboração conjunta do conhecimento. Para as aulas terem essas funções, pede-se para os estudantes fazerem em casa o que tradicionalmente se fazia em classe. Assistir aulas (em vídeos) e ler textos, cada qual faz no seu ritmo; onde e quando lhe for possível. No Ensino de Física, o Peer Instruction (MAZUR, 1997), sem dúvida, é a estratégia de inversão de sala de aula mais popular entre professores e pesquisadores.

A atribuição de deveres de casa é uma prática cultural compartilhada por professores, estudantes e suas famílias, mas, apesar disso, tem sido pouco investigada e problematizada (CARVALHO, 2004). Resende (2008) apresenta resultados de pesquisa que sinalizam que as famílias atribuem grande importância aos deveres de casa. Por outro lado, Carvalho e Serpa

\footnotetext{
${ }^{2}$ Usaremos dever de casa e tarefa para casa como sinônimos.
} 
(2006) identificaram que os deveres de casa podem gerar desgaste emocional nos estudantes e em suas famílias, sobretudo nas de nível socioeconômico mais baixo.

Dettmerset et al. (2010) e Carvalho (2004) destacam a inexistência, na literatura de pesquisa, de evidências conclusivas a respeito do impacto dos deveres de casa sobre o desempenho acadêmico dos estudantes. Já Carvalho e Serpa (2006) defendem que a eficácia dos deveres de casa depende de um planejamento pedagógico coerente. Nisso reside nossa aposta na elaboração e atribuição de deveres de casa aos estudantes: tarefas de curta duração, articuladas à proposta curricular do curso de física, podem fazer diferença no engajamento dos estudantes nas tarefas e no seu desempenho escolar.

A partir dessa aposta, criamos deveres de casa em ambiente virtual como um elo entre os conteúdos já abordados e aqueles que ainda seriam abordados. Essas tarefas deram condições para que, em sala de aula, os estudantes assumissem o protagonismo no seu processo de aprendizagem através da reflexão, exposição e discussão ativa de ideias sobre os conceitos e fenômenos físicos abordados.

Trabalhamos numa escola pública pertencente à Rede Federal de Educação Profissional, Científica e Tecnológica. Os estudantes têm em torno de 35 aulas de 50 minutos por semana e muitas tarefas extraclasse das várias disciplinas que cursam. Apesar disso, temos evidências de que estamos conseguindo engajar os estudantes nessas atividades e tornálas relevantes para o processo de aprendizagem em física.

Fizemos este relato de experiência com o propósito de caracterizar nossa trajetória de elaboração dos deveres de casa; apresentar as bases teóricas e os princípios que nos orientaram nessa elaboração; exemplificar nosso relato com a apresentação de um dever sobre dinâmica newtoniana; e apresentar resultados da avaliação dessas tarefas por nossos estudantes. Este texto registra um processo de identificação de possibilidades diante de desafios em relação ao trabalho escolar. Não apresentamos uma receita. Mesmo assim, nos dirigimos a estudantes de licenciatura, professores e professoras interessados em implementar deveres de casa em seus cursos ou em modificar os deveres que já atribuem a seus estudantes. Esperamos que nossa experiência possa favorecer a reflexão a respeito dos deveres de casa e do papel que podem vir a desempenhar em planejamentos pedagógicos específicos. Em outras palavras, desejamos criar condições para a reelaboração de nossa experiência para o contexto daqueles que possam se interessar e se identificar com o que fizemos.

\section{Aulas de Física: discussão, reflexão e (re)elaboração conjunta de ideias}

Há quase três décadas, Lillian McDermott (1993) publicou um artigo que trata do descompasso entre como a Física é ensinada e como os estudantes aprendem. Baseando-se em resultados de pesquisas (e.g. MCDERMOTT; SHAFFER, 1992; TROWBRIDGE; MCDERMOTT, 1981), ela argumenta que o ensino tradicional, centrado nas ações do professor, é ineficaz para a maioria dos estudantes porque não favorece a compreensão funcional de conceitos e modelos, bem como de aspectos relacionados ao fazer científico. 
Professores de Física tanto da Educação Básica, quanto da Educação Superior, podem não ter plena consciência sobre esse descompasso, mas experimentam cotidianamente os seus efeitos em sala de aula: baixos níveis de aprendizagem e desinteresse pelo estudo da disciplina (POZO; GÓMEZ, 1998). Claro que a falta de sintonia entre como se aprende e como se ensina não é uma exclusividade nem de nossa área de conhecimento, nem do tempo em que vivemos. Há várias décadas, autores de diferentes áreas abordam essa questão sob diversas perspectivas e com propósitos distintos (Cf. BEREITER; SCARDAMALIA, 1996; DEWEY, 1997; FREIRE, 1996; OLSON; BRUNER, 1996).

Membros da comunidade de pesquisadores e professores de Física têm se mobilizado para encontrar saídas para esse problema. Para isso, têm se apoiado no vasto conjunto de resultados acumulados pelo campo das pesquisas em Ensino de Física para conceber materiais didáticos, estratégias de ensino e atividades para sala de aula que conferem aos estudantes protagonismo e autonomia no próprio processo de aprendizagem (Cf. HENDERSON; DANCY, 2009). A despeito desses esforços que visam à renovação e à melhoria do ensino, não ocorreram mudanças significativas nas práticas de ensino adotadas nas aulas de física. Os casos que conhecemos são inciativas isoladas. Na maioria das salas de aula de Física, no Brasil e no mundo, o Ensino não é baseado na Pesquisa em Ensino (VAZ; JULIO; FARIA, 2012).

Entre todas as estratégias de ensino baseadas em pesquisa que conhecemos, há uma que tem crescido em popularidade entre professores de Física: o Peer Instruction (PI) - ou estratégia de instrução por pares - elaborado por Eric Mazur (1997). Não sabemos ao certo a causa dessa popularidade, mas é provável que a facilidade e o baixo custo de implementação, a reação positiva inicial da maioria dos estudantes, os bons resultados que se tem conseguido em termos de aprendizagem conceitual e o prestígio de seu idealizador tenham contribuído para isso. De maneira geral, tal estratégia consiste na criação de oportunidades de aprendizagem em sala de aula nas quais os estudantes avaliam e (re)elaboram sua compreensão sobre conceitos e modelos científicos por meio de discussões de questões propostas pelo professor. Esta é a dinâmica normalmente empregada: ao longo das aulas, o professor (i) propõe questões para que os estudantes respondam-nas individualmente; (ii) avalia o conjunto de respostas da turma - se o resultado geral supera um valor de referência, passa-se à próxima questão; se não, pede aos estudantes que argumentem/contra-argumentem com colegas que marcaram resposta diferente da sua de modo a chegarem a um convencimento da resposta correta; (iii) repete a questão e, novamente, avalia o conjunto das respostas; (iv) com base no resultado obtido, decide ou não explicar a questão à classe.

A estratégia em si é simples, mas permite algo muito valioso do ponto de vista educacional que, mesmo hoje, não é comum nas aulas de Física: conceder protagonismo aos estudantes. Alguém pode usar Peer Instruction por estar na moda. Nós, porém, ocasionalmente o usamos como uma maneira de engajar os estudantes em discussões que favoreçam a argumentação e a reflexão sobre conceitos e modelos científicos, bem como a 
(re)elaboração conjunta de ideias. Nisso reside o potencial de ampliação do domínio conceitual dos estudantes (FAGEN; CROUCH, 2002; LASRY; MAZUR; WATKINS, 2008; LENAERTS; WIEME; ZELE, 2003; SMITH et al., 2009; SUPPAPITTAYAPORN; EMARAT; ARAYATHANITKUL, 2010).

A implementação do PI demanda uma reorganização do ambiente de aprendizagem da sala de aula, bem como dos papeis tradicionalmente desempenhados por professores e estudantes. Atualmente, usa-se o termo flipped classroom $^{3}$ para designar essa mudança. Em classe, os estudantes passam a usar o tempo para tarefas consideradas mais nobres como discussão com colegas e professor sobre fenômenos, conceitos e modelos científicos, bem como a resolução de problemas e desafios em grupo. O professor passa a colaborar com os estudantes e a gerenciar os conhecimentos relacionados às aulas. Ao invés de transmitir informações, o professor provê condições para a discussão e para a (re)elaboração conjunta de ideias (BERGMANN; SAMS, 2012; OLIVEIRA; ARAUJO; VEIT, 2016; REIDSEMA et al., 2007). A inversão da sala de aula demanda cuidado, tanto com as atividades desenvolvidas em classe, quanto com o planejamento das tarefas a serem realizadas em casa, uma vez que há uma interdependência entre ambas.

\section{O papel de tarefas para casa em salas invertidas}

Temos observado que, apesar de não contabilizarem horas para a integralização curricular, as tarefas para casa são muito empregadas na Educação Básica e na Educação Superior. No Ensino de Física, essas tarefas consistem, tradicionalmente, em exercícios de fim de capítulo, muitos dos quais envolvem manipulação algébrica (BONHAM; DEARDORFF; BEICHNER, 2003).

A atribuição de tarefas para casa pelos professores é, geralmente, marcada pelo compromisso com a continuidade ou com a ampliação das experiências iniciadas em sala de aula e, consequentemente, com a melhoria dos níveis de aprendizagem dos estudantes. Contudo, é controversa a relação entre a realização de tarefas para casa e o desempenho acadêmico. De acordo com Dettmerset et al. (2010), fragilidades metodológicas de muitos estudos sobre essa questão impedem conclusões robustas a esse respeito.

Alguns autores propõem que tarefas de qualidade são aquelas cujas abordagens são coerentes com aquilo que foi trabalhado com os estudantes em sala de aula e cujo desafio cognitivo está dentro das possibilidades de quem aprende (Cf. DETTMERS et al., 2010; FISHER; LAPP; FREY, 2011). Esses autores apresentam uma concepção tradicional de tarefas para casa que se baseia na aplicação direta do que foi ensinado em sala de aula.

\footnotetext{
3 O termo flipped classroom - sala de aula invertida - é atribuído a Bergmann e Sams (2012). Ele ganhou notoriedade nos últimos anos, dentro e fora do campo do Ensino de Ciências. Contudo, a estratégia de ensino associada a esse termo não é, necessariamente, uma novidade (Cf. OLIVEIRA; ARAUJO; VEIT, 2016). A estratégia de instrução por pares surgiu primeiro.
} 
As tarefas para casa usadas em classes invertidas são dotadas de outra orientação pedagógica: proporcionar o primeiro contato dos estudantes com novos conteúdos de modo que o tempo de aula seja usado para discussão, resolução de problemas e aplicação dos novos conhecimentos. Por essa razão, frequentemente, as tarefas para casa atribuídas aos estudantes de classes invertidas consistem em assistir vídeos, realizar estudos dirigidos e tutoriais, ler textos selecionados, lidar com simulações computacionais etc. (BERGMANN; SAMS, 2012; JENSEN et al., 2018; MAZUR, 1997; REIDSEMA et al., 2007). Tivemos acesso a um único estudo sobre esse tipo de tarefa para casa no qual Jensen et al. (2018) investigaram o efeito gerado por três tipos de tarefas para casa sobre a aprendizagem de estudantes: tutoriais interativos online, aulas em vídeo e leitura de textos didáticos. Os resultados indicam que as tarefas para casa baseadas em aulas gravadas em vídeo, se comparadas aos outros dois tipos de tarefas, levam pequena vantagem na promoção da aprendizagem.

Independente da orientação pedagógica das tarefas para casa, a verificação das tarefas pelo professor e sua discussão com os estudantes é fundamental para que se consiga impactar positivamente a aprendizagem (ROSÁRIO et al., 2015). Os resultados de Bonham, Deardorff e Beichner (2003) mostram que tarefas online e tarefas de lápis e papel, ambas avaliadas pelo professor, favorecem o aprendizado dos estudantes de maneira semelhante, ou seja, neste quesito, um tipo não se mostra melhor que o outro. Para esses autores, os ganhos de aprendizagem estão associados não ao formato das tarefas, mas ao suporte que os estudantes recebem do professor na forma de retornos em sala de aula. Cheng et al (2004) e Mestre et al. (2002) trazem resultados que são complementares a esses. Eles mostram que tarefas online avaliadas pelo professor favorecem a aprendizagem de maneira mais efetiva se comparadas às tarefas de lápis e papel que não são corrigidas ou que às vezes são corrigidas pelo professor. Sob o ponto de vista do ensino, esses resultados mostram que as vantagens das tarefas online são redução da sobrecarga de trabalho sobre o professor, aumento da agilidade na correção das tarefas e a possibilidade de se planejar melhor o retorno aos estudantes em sala de aula.

\section{Contexto Educacional e Desafio Enfrentado}

Somos professores do quadro permanente do Colégio Técnico da Universidade Federal de Minas Gerais (COLTEC/UFMG) - escola de nível médio, vinculada à Secretaria de Educação Profissional e Tecnológica do Ministério da Educação (SETEC/MEC). Na equipe de Física, desenvolvemos uma prática de trabalho colaborativo. Por exemplo, temos reuniões semanais para questões gerais, administrativas e pedagógicas. Também fazemos reuniões semanais de ensino por série. Essas "coordenações de série" funcionam como espaço de debate, inovação e formação continuada. Nelas, dedicamo-nos a avaliar e planejar o curso e as aulas. Resolvemos questões práticas recorrendo tanto a experiências pessoais em ensino, quanto à literatura de pesquisa. Constantemente, introduzimos inovações pedagógicas e curriculares no curso de Física. 
Há nove anos, Física é ensinada só na $1^{\mathrm{a}}$ e na $2^{\mathrm{a}}$ série. Há um ano, a carga horária semanal de física em cada série foi reduzida a quatro aulas de 50 minutos. Na $1^{\text {a }}$ série, todos cursos técnicos têm duas aulas em classe e duas no laboratório. $\mathrm{Na} 2^{\mathrm{a}}$ série, os estudantes de dois cursos (Automação Industrial e Eletrônica) também têm duas aulas em classe e duas no laboratório. Já os estudantes dos outros três cursos (Análises Clínicas, Desenvolvimento de Sistemas e Química) têm as quatro aulas em classe.

A atribuição regular de tarefas para casa aos estudantes e a avaliação dessas tarefas faz parte da cultura do curso de Física do COLTEC há pelo menos duas décadas. Cerca de vinte por cento dos pontos de cada trimestre letivo são atribuídos às tarefas desenvolvidas em classe e em casa. Há 20 anos, deveres de casa eram estudos dirigidos baseados no livro texto da época: "Imagens da Física" de Ugo Amaldi (1995). Eles cumpriam a função de desenvolver nos estudantes estratégias e habilidades de leitura e escrita, bem como de prepará-los para o que seria trabalhado na aula seguinte. Desde aquela época, a demanda de leitura para casa mudou nossa estratégia de aula. No início, avaliações da interpretação de texto passaram a ser feitas regularmente. Por exemplo, aplicávamos testes de múltipla escolha e questões do tipo "Verdadeiro ou Falso" nos dez minutos iniciais da aula. Enquanto os estudantes realizavam novas leituras ou exercícios, o professor corrigia os testes, os devolvia e comentava, muitas vezes, na mesma aula.

Há nove anos, quando o currículo de física da escola foi reformulado, um de nós coordenava a $2^{\mathrm{a}}$ série e propôs o uso de Atividades Orientadas pela Pesquisa (AOP): que são atividades desenvolvidas a partir de estratégias de ensino e recursos didáticos baseados em resultados de pesquisas. São exemplos de AOPs os Tutoriais de Física Introdutória (MCDERMOTT; SHAFFER, 2002), a Estratégia de Instrução por Pares (MAZUR, 1997), as atividades de laboratório por investigação e uso desimulações computacionais como as do $\mathrm{PhET}^{4}$. Quando decidimos escrever este artigo, nós éramos da equipe de três professores da $2^{\mathrm{a}}$ série; um há nove, outro há sete anos.

Hoje, as atividades didáticas de classe, nas turmas da $2^{\mathrm{a}}$ série, são baseadas, predominantemente, nos Tutoriais de Física Introdutória (MCDERMOTT; SHAFFER, 2002). Esses tutoriais consistem em sequências de pequenas tarefas com foco em temas fundamentais da Física. Essas tarefas são planejadas para serem abordadas por pequenos grupos. Geralmente, elas são compostas de sequências de questões de lápis e papel. Algumas delas incluem manipulação experimental com materiais simples. Tais tarefas foram criadas com base em dificuldades de aprendizagem e concepções dos estudantes descritas na literatura de pesquisa em Ensino de Física. Elas foram concebidas para serem aplicadas por monitores em seções complementares às aulas centradas no professor, em grandes auditórios, no Ensino Superior.

O texto desses tutoriais, em particular, contrapõe ideias errôneas de estudantes a ideias consagradas da física e isso causa desconforto nos estudantes. Tais contrapontos e

\footnotetext{
$4<$ https://phet.colorado.edu/>.
} 
outras estratégias problematizadoras forçam o engajamento cognitivo, o que tende a propiciar aos estudantes: compreensão funcional dos conceitos básicos da Física e o desenvolvimento de estratégias gerais de raciocínio. Os desafios que os tutoriais colocam para as turmas criam, para nós, professores de ensino médio, oportunidade de confrontar ideias do senso comum com ideias científicas. O estímulo ao conflito cognitivo é deliberado. Os autores do material resumem a estratégia de implementação dos tutoriais em três passos: a) preparar o estudante para os novos conteúdos e evocar suas ideias sobre conceitos relacionados; b) confrontar essas ideias com evidências fornecidas pelo tutorial; c) resolver as inconsistências entre as ideias prévias e os conceitos científicos.

Embora, originalmente, os tutoriais tenham sido criados para os cursos de física básica dos anos iniciais de universidades americanas, há evidências de adaptações bemsucedidas dessa estratégia para a Educação Básica (BENEGAS; FLORES, 2014; BENEGAS, 2007; FARIA; VAZ, 2018; TUYAROT; EIRAS, 2011). Ao nos inspirarmos nesses tutoriais, tivemos que fazer adaptações progressivas ao nosso contexto. Isso envolveu autoria. Nosso conhecimento da pesquisa em ensino nos serve tanto para frear o ímpeto de alterar o texto desses tutoriais, quanto para dar nosso próprio tom ao curso. Às intervenções nos pequenos grupos e à condução das aulas para turma toda, acrescentamos inúmeras medidas pedagógicas estratégicas.

Nos três primeiros anos em que trabalhamos com os tutoriais, o fizemos sem apoio de outros recursos mediacionais ou pedagógicos. O único cuidado que tivemos foi o de adaptar os tutoriais para as dinâmicas de nossas aulas. Com isso enfrentamos dificuldades e resistência dos nossos estudantes à nova metodologia. Muitos, ao verem suas concepções espontâneas confrontadas com os conceitos científicos, sentiam-se ansiosos e desprestigiados. Além disso, demandavam materiais de apoio para se prepararem para as aulas e para estudarem após elas. Esses fatos foram desafiadores. Implementamos várias ações que se mostraram bem sucedidas pois a resistência e as queixas dos estudantes em relação à metodologia de ensino adotada praticamente desapareceram: introduzimos tarefas para casa regulares que faziam uma conexão entre as aulas já dadas e as aulas que ainda seriam dadas. Essas tarefas eram feitas com o auxílio de computador. No início das aulas, dávamos retorno sobre as tarefas para casa e usávamos a estratégia de ensino por pares para retomar essas tarefas; passamos a fazer preleções rápidas (10 a 15 minutos) em que recordávamos o que já havia sido trabalhado e introduzíamos os novos conteúdos que seriam abordados naquela aula. Essas preleções e a condução da aula eram personalizadas com base nos resultados das tarefas para casa de cada turma; passamos a levar para a sala recursos mediacionais extras como demonstrações, animações, vídeos e simulações.

Neste relato, nos restringimos às tarefas para casa. A maneira como as implementamos levou muitos estudantes a terem experiências educativas em classe, dada a oportunidade de refletirem sobre conceitos e modelos científicos já trabalhados e de se prepararem para entenderem os conceitos e modelos científicos a serem abordados nas aulas. 
Isso contribuiu para a redução da ansiedade dos estudantes e para o aumento da confiança neles mesmos; em especial, em relação aos desafios que os tutoriais lhes colocavam. Para conseguir isso, tivemos que abandonar o modelo dos estudos dirigidos e implementar tarefas com potencial de reflexão sobre os tópicos tratados sem classe.

\section{Nossas Tarefas para Casa}

A revisão que fizemos da literatura de pesquisa nos revelou que tarefas para casa de qualidade devem ser coerentes com os conteúdos e com as estratégias de abordagem desses conteúdos em sala de aula. Nesse espírito, elaboramos tarefas ajustadas às demandas de um curso de física com atividades inspiradas pelos Tutoriais de Física Introdutória (MCDERMOTT; SHAFFER, 2002). Elas foram associadas à outra estratégia de ensino - a instrução por pares (MAZUR, 1997) - para que pudéssemos trabalhar as dificuldades demonstradas pelos estudantes nas respostas dadas às tarefas para casa.

Passamos a coletar informações sobre o entendimento conceitual desses estudantes de maneira a oferecer um curso melhor ajustado a cada turma. Em linhas gerais, cada tarefa para casa foi elaborada considerando-se os seguintes objetivos:

- Ampliar as experiências iniciadas em classe com os tópicos de ensino específicos;

- Preparar os estudantes para a aprendizagem de novos tópicos que seriam abordados em sala;

- Avaliar a compreensão de tópicos abordados ou com abordagem em andamento;

- Favorecer o automonitoramento pelos estudantes do processo de aprendizagem;

- Ampliar e potencializar os tempos dedicados ao trabalho em grupo e à discussão e elaboração conjunta de ideias em sala;

Construímos nossas tarefas com o Formulários $^{5}$, ferramenta da Google. Fizemos essa escolha após avaliar outras ferramentas e plataformas que tínhamos à disposição. Escolhemos os formulários, pois sua facilidade de acesso aumentaria a possibilidade de compartilhar as tarefas que elaboramos. Sempre procuramos dividir nosso trabalho com quem deseja - especialmente, outros professores de física e estudantes.

Formulários é uma ferramenta que permite criar questões de diferentes tipos: abertas, múltipla escolha, caixas de seleção, escala linear etc. Ela permite inserção de figuras e vídeos nas questões. Também corrige as respostas automaticamente e depois envia uma avaliação de desempenho a cada estudante, inclusive com comentários - individualizados ou padronizados - escritos por nós para a resposta de cada questão. As respostas dos estudantes são disponibilizadas em interface gráfica da própria ferramenta ou em planilha eletrônica.

No link a seguir, disponibilizamos um exemplo de dever de casa, atribuído em 2019, que aborda questões relacionadas à Dinâmica Newtoniana. Seu foco está na $1^{\mathrm{a}}$ e na $2^{\mathrm{a}}$ leis de Newton. Ela é constituída pela leitura de algumas páginas de livro didático; por uma síntese

\footnotetext{
$5<$ https://www.google.com/intl/pt-BR/forms/about/>.
} 
do texto a ser elaborada pelos estudantes; e por sete questões de múltipla escolha que se relacionam diretamente à atividade desenvolvida em sala sobre o mesmo tema.

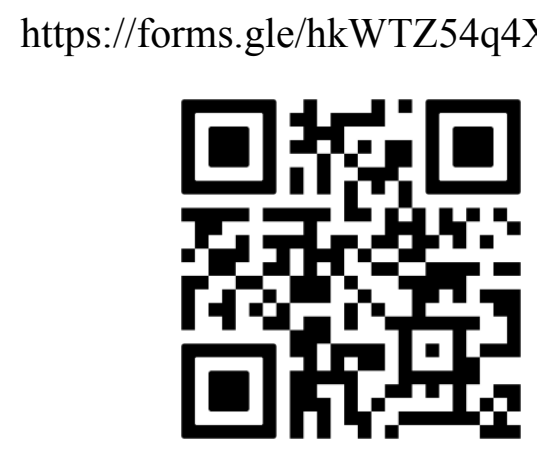

O quadro 1 caracteriza o contexto pedagógico em que esse dever de casa foi atribuído aos estudantes com a apresentação das atividades desenvolvidas em sala de aula, antes e depois de receberem o dever.

Quadro 1 - Antes e depois do dever de casa sobre mecânica newtoniana ${ }^{6}$.

\begin{tabular}{|c|c|c|}
\hline 2018 (1 ${ }^{\circ}$ Ano) & \multicolumn{2}{|c|}{$2019\left(2^{\circ}\right.$ Ano $)$} \\
\hline $\begin{array}{c}\text { Tratamento da } \\
\text { Dinâmica no Curso de } \\
\text { Física }\end{array}$ & $\begin{array}{c}\text { Antes do Dever de Casa } \\
\text { Tutorial de Forças } \\
\left(1^{\mathrm{a}} \text { aula }\right)\end{array}$ & $\begin{array}{c}\text { Após o Dever de Casa } \\
\text { Tutorial de Forças } \\
\text { (Continuação) }\end{array}$ \\
\hline $\begin{array}{l}\text { Abordagem das Leis de } \\
\text { Newton no contexto da } \\
\text { segurança no trânsito. }\end{array}$ & $\begin{array}{l}\text { O professor propôs aos estudantes } \\
\text { tarefas baseadas no tutorial } \\
\text { intitulado "Forças" } \\
\text { (MCDERMOTT; } \\
\text { 2002, p. 21-24), no qual se busca } \\
\text { construir uma definição } \\
\text { operacional desse conceito. Nessa } \\
\text { que foi a primeira aula sobre } \\
\text { dinâmica, os estudantes } \\
\text { elaboraram e discutiram } \\
\text { coletivamente o Diagrama de } \\
\text { Corpo Livre (DCL) de um objeto } \\
\text { empurrado/puxado por duas } \\
\text { pessoas, como mostrado na figura } \\
\text { abaixo. } \\
\text { Jô } \$ \text { P }\end{array}$ & $\begin{array}{l}\text { Elaboração coletiva de DCL de um } \\
\text { livro sobre a mesa; e desse livro } \\
\text { com outro maior sobre ele, como } \\
\text { mostrado na figura abaixo. } \\
\text { Solicitou-se o DCL dos dois livros, } \\
\text { o de cima e o debaixo. Para lidarem } \\
\text { com essa situação, os estudantes } \\
\text { precisam lançar mão do } \\
\text { conhecimento que tem sobre a } 3^{\text {a }} \\
\text { Lei (Ação e Reação). }\end{array}$ \\
\hline
\end{tabular}

\footnotetext{
${ }^{6}$ As figuras apresentadas no quadro 1 foram extraídas de McDermott e Shaffer (2002), p. 21-24.
} 
A tarefa para casa que apresentamos como exemplo foi atribuída aos estudantes do $2^{\circ}$ ano após a aula inicial sobre dinâmica. No ano anterior ( $1^{\circ}$ ano), os estudantes tiveram contato com as leis de Newton numa sequência de ensino que buscava contextualizar o assunto por meio do tema segurança no trânsito.

A leitura proposta no dever vincula-se à aula anterior a sua atribuição e às aulas subsequentes, pois apresenta e discute as leis de Newton e alguns exemplos clássicos. O texto permite refletir sobre os diagramas de corpo livre elaborados na $1^{\mathrm{a}}$ aula, instrumentaliza os estudantes para lidarem com as próximas tarefas e os qualificam para as discussões em grupo.

As questões de múltipla escolha são de três tipos: (i) as que apresentam desafios semelhantes aos tratados em sala, em novos contextos, e demandam a articulação da $1^{\mathrm{a}}$ e da $2^{\mathrm{a}}$ Leis de Newton para a sua resolução (questões 2 a 6); (ii) as que apresentam desafios e contextos semelhantes aos tratados em sala, na aula anterior, e demandam a articulação da $1^{\mathrm{a}} \mathrm{e}$ da $2^{\mathrm{a}}$ leis de Newton para sua resolução (questões 7 e 8); as que apresentam desafios semelhantes aos tratados em sala, em novos contextos, que, alternativamente, podem envolver articulação também da $3^{\text {a }}$ lei de Newton em sua resolução (questão 2). Dessa forma, essas questões de múltipla escolha permitem que os estudantes repensem nos assuntos abordados em sala em aulas anteriores, que avaliem sua compreensão sobre esses assuntos, que tenham novas oportunidades de mobilizar os conceitos e teorias vistos em sala e que tenham a oportunidade de lançar mão de conceitos com os quais já tiveram algum contato e que serão revisitados nas aulas seguintes.

O Formulários faz a correção automática dessas questões e apresenta o resultado global da turma em interface gráfica, como neste exemplo, em que apresentamos os resultados da questão 7:

Gráfico 1 - Exemplo de gráfico gerado pelo Formulários.

7) Na figura, Jô empurra o bloco. A força que Jô exerce sobre o bloco tem as seguintes características:(i) é uma força de contato; (ii) é horizontal; (iii) é da direita para esquerda.

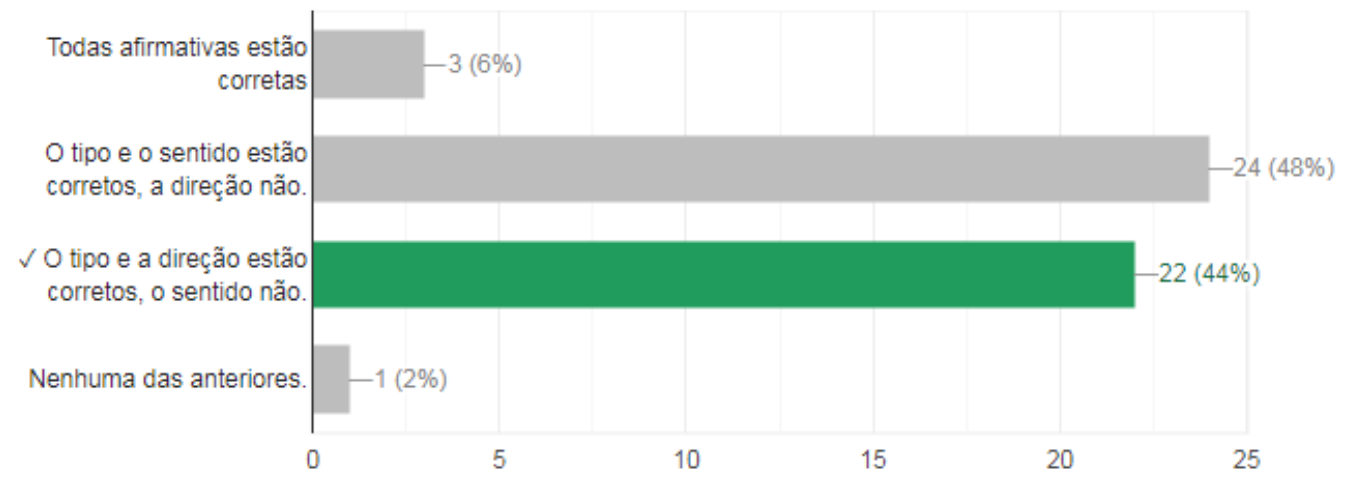


Esse exemplo mostra a praticidade e a facilidade da rápida visualização pelo professor dos resultados globais de cada turma. Nesta turma, por exemplo, metade dos estudantes confundem direção e sentido, por exemplo. Antes ou mesmo durante uma aula em curso, o professor pode acessar esses resultados e tomar decisões sobre a melhor forma de conduzi-la. Tem-se a oportunidade de personalizar a aula para cada turma. Podemos priorizar a abordagem tópicos difíceis para muitos estudantes ou dar atenção individual a poucos estudantes, face suas dificuldades de compreensão ou mesmo de expressão escrita nas respostas a questões abertas. Quando suspeitamos da necessidade de intervenções com estudantes específicos, consultamos os relatórios nos quais estão disponíveis todas as respostas dadas por um mesmo sujeito.

Geralmente, usamos essas informações para planejar a estratégia de instrução por pares: elaboramos conjuntos de questões de múltipla escolha focadas nas dificuldades mais comuns dos estudantes nas tarefas para casa. Administramos as questões pertinentes no início da primeira aula após o encerramento do prazo para envio das respostas. Projetamos uma questão por vez conforme a estratégia de instrução por pares descrita na segunda seção. Usamos o aplicativo Plickers ${ }^{7}$. Ele coleta respostas de todos os estudantes em menos de um minuto e gera gráficos que nos informam o estado de desenvolvimento dos estudantes. Tomamos decisões sobre a condução da aula com base nesses gráficos.

Durante a instrução por pares, damos retorno aos estudantes sobre as tarefas para casa. Relacionamos as questões propostas em sala com aquelas propostas para serem desenvolvidas em casa. Em geral, os estudantes se engajam de maneira exemplar nessa dinâmica seja pelo fato das questões das sessões de instrução por pares estarem centradas em suas principais dificuldades, seja pelo apelo tecnológico associado ao uso do aplicativo Plickers.

\section{Avaliação das Tarefas pelos Estudantes}

Os dados apresentados a seguir foram obtidos de um processo de avaliação do curso de física pelos estudantes no final dos anos letivos de 2017 e de 2019. São registros que fizemos enquanto professores. O propósito original dessas avaliações era gerar informações com potencial de reflexão e melhoria de nossas atividades de ensino. Recorremos também a informações produzidas pelos professores das turmas em planilha de avaliação para saber sobre a taxa de envio de respostas pelos estudantes dos deveres de casa que foram atribuídos.

Nas duas ocasiões de avaliação, pedimos aos estudantes que respondessem a um questionário de forma voluntária e anônima. Em 2017, dos 95 estudantes convidados à avaliação dos deveres, 81 fizeram-na. Esses estudantes pertenciam aos cursos técnicos de Análises Clínicas, Informática e Automação Industrial. Em 2019, dos 69 estudantes

\footnotetext{
$7<$ www.plickers.com>.
} 
convidados, 56 nos enviaram suas respostas às questões de avaliação. Esses estudantes estavam matriculados nos cursos técnicos de Química e de Eletrônica.

Perguntamos aos estudantes sobre o interesse deles em fazer as tarefas para casa. Como se pode ver no gráfico 2, a soma dos estudantes que relataram nenhum ou baixo interesse em fazer os deveres de casa atingiu cerca de 45\% no ano de 2017 e $55 \%$ no ano de 2019. Declararam muito interesse em fazer os deveres cerca de 30\% em 2017 e 5\% em 2019. Esses resultados indicam que, no geral, o interesse dos estudantes foi baixo.

Gráfico 2 - Interesse dos estudantes pelas tarefas para casa de Física.

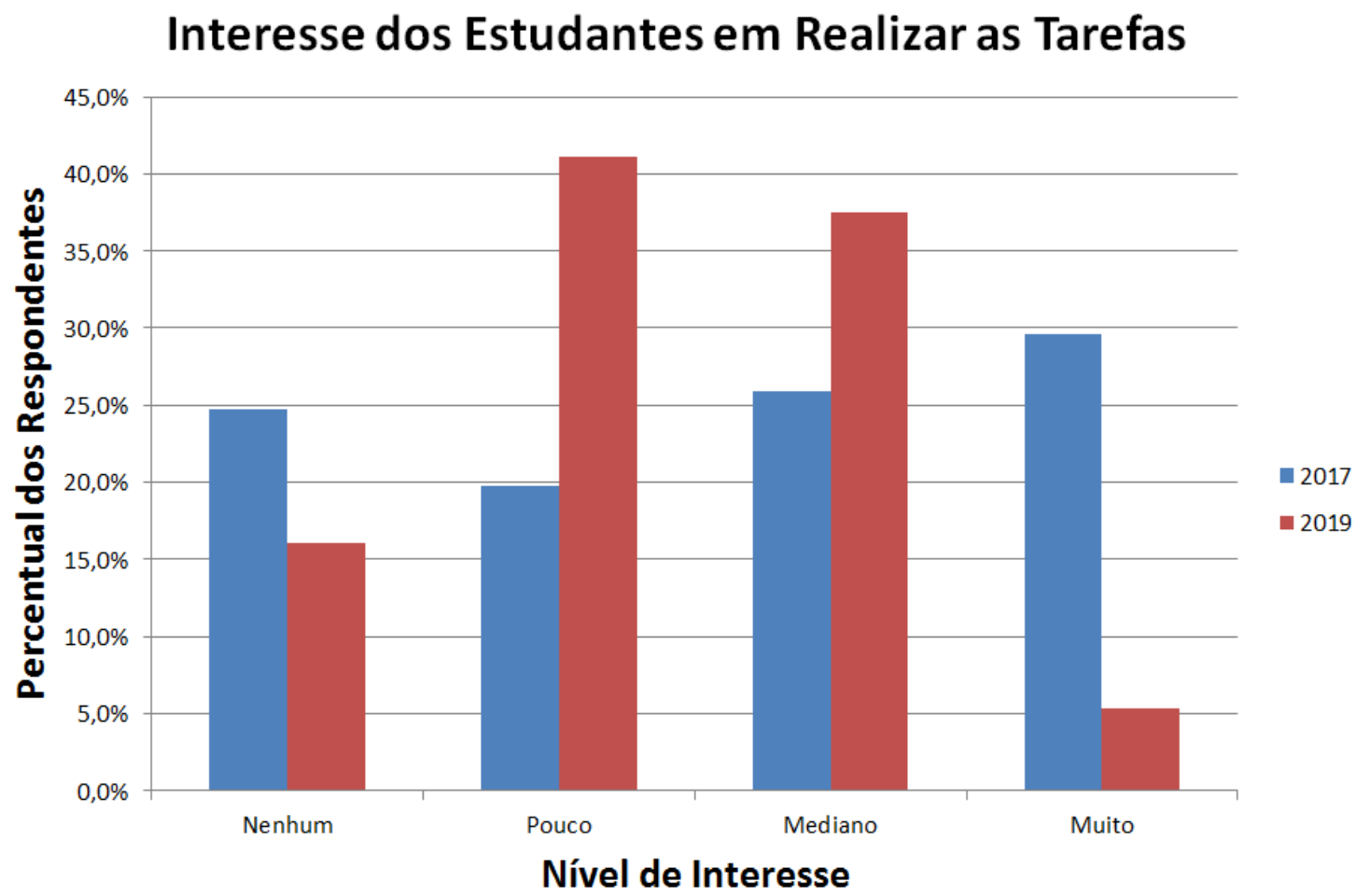

Ao longo do ano letivo de 2017, atribuímos aos estudantes 20 deveres para casa. Em 2019, esses 20 deveres (com pequenas adaptações) e mais dois foram designados. Os gráficos 3 e 4 mostram o percentual de tarefas/deveres entregues por turma. Em 2017 (gráfico 3), no curso de Análises Clínicas, a média de tarefas entregues ficou em torno de 90\%; no curso de Automação Industrial $^{8}$, em torno de $80 \%$; e no curso de Informática, em torno de $70 \%$. Em 2019 (gráfico 4), no curso de Química, a taxa média de entrega foi de, aproximadamente, $75 \%$. No curso de Eletrônica, esse valor ficou em torno de $65 \%$.

\footnotetext{
${ }^{8}$ Nessa turma, por questões operacionais, guardamos o registro do $8^{\circ}$ dever de casa em diante.
} 
Gráfico 3 - Percentual de tarefas entregues por turma (2017).

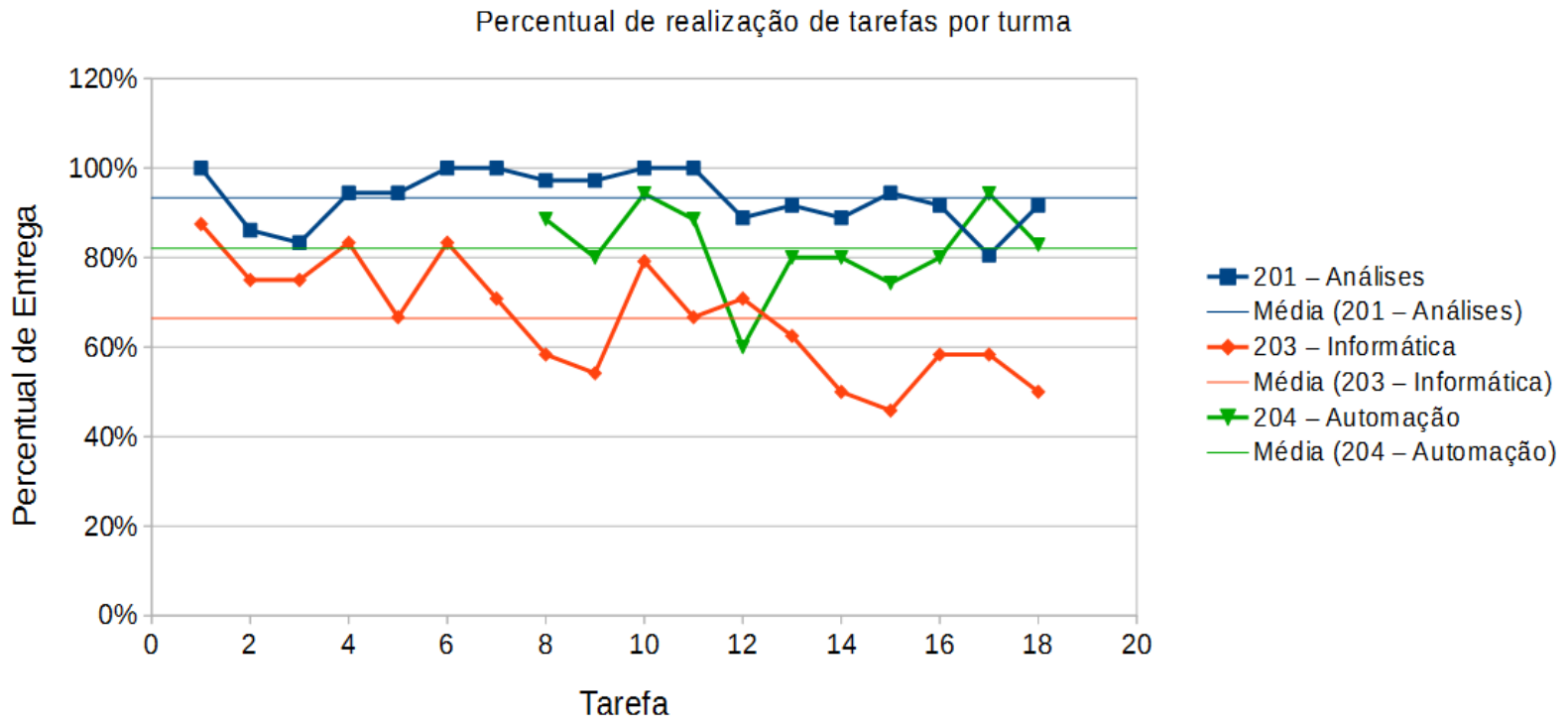

Gráfico 4 - Percentual de tarefas entregues por turma (2019).

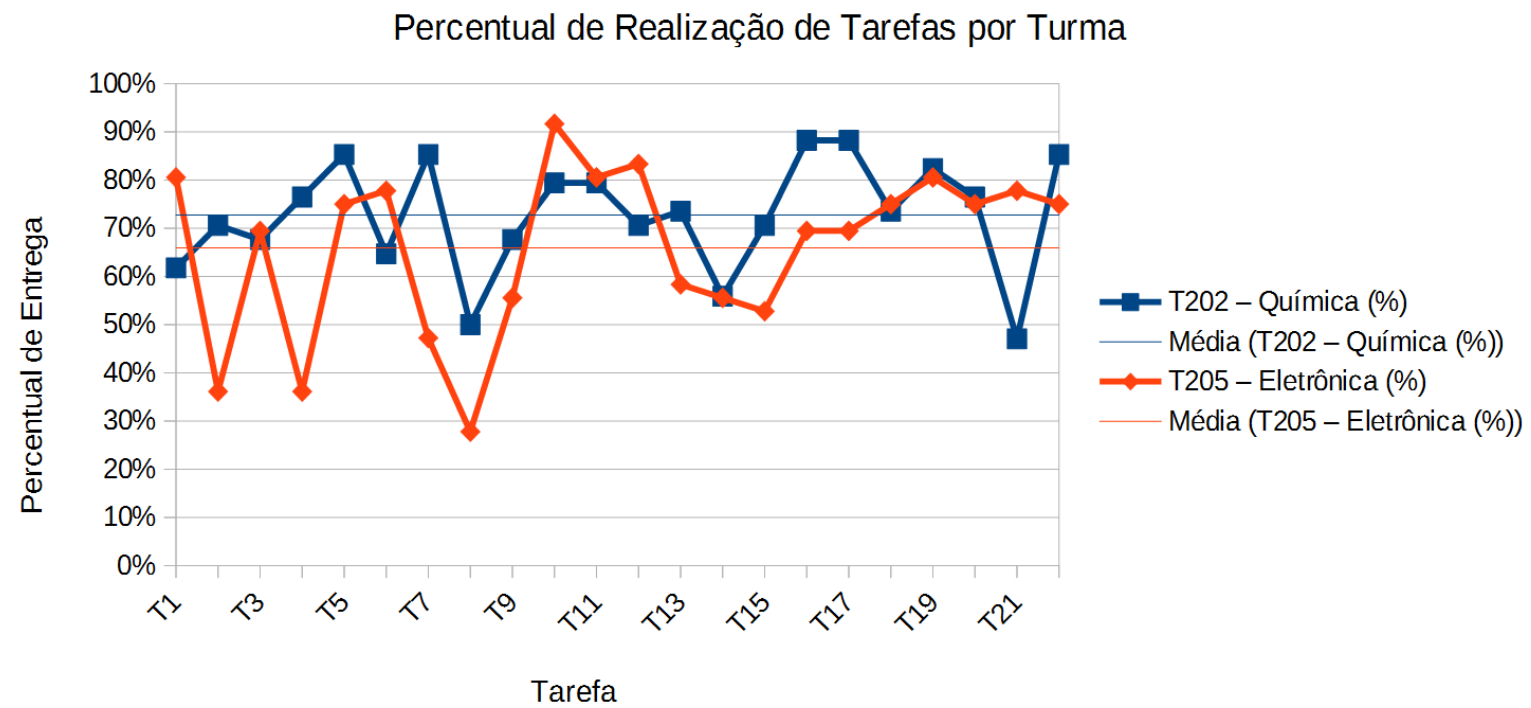

Percentualmente, as turmas de 2017 entregaram mais tarefas que as turmas de 2019. Apesar dessa diferença, a média de entrega desses deveres pelos estudantes foi elevada se considerarmos que estes passam o dia todo na escola e possuem pouco tempo para realizarem atividades extraclasse. Além disso, os deveres de física não eram os únicos a que tinham que se dedicar. 
Perguntamos se os estudantes copiaram as respostas das tarefas de algum colega. Pensávamos que o índice de cópia fosse alto, considerando as restrições de tempo livre dos estudantes e a facilidade de compartilhar repostas por e-mail ou aplicativos de mensagem. Contudo, os resultados apresentados no gráfico 5 nos surpreenderam positivamente. Gráfico 5 - Percentual de tarefas entregues por turma.

\section{Frequência de Cópia das Tarefas}

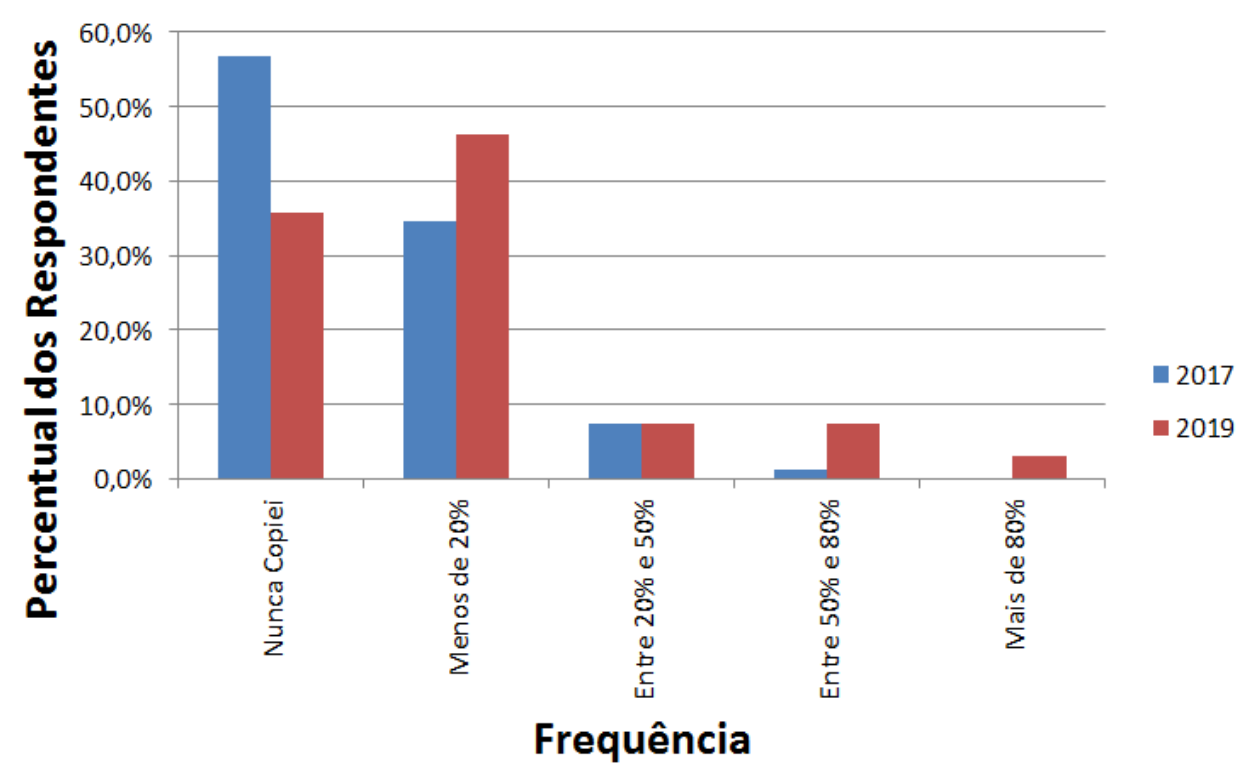

Percentualmente, menos estudantes copiaram respostas dos colegas em 2017, em comparação com 2019. Contudo, em cada um dos dois anos, se somarmos os estudantes que nunca copiaram respostas com os que admitiram a prática e indicaram que o fizeram em menos de $20 \%$ dos deveres, temos um percentual de $80 \%$ dos estudantes. Esse resultado sugere baixo índice de cópias. Tanto em 2017, quanto em 2019, os estudantes foram perguntados sobre o que os levou a copiar as respostas dos deveres. Prevaleceu como justificativa, direta ou indireta, a falta de tempo.

$\mathrm{O}$ fato de termos conseguido altas taxas de entrega e baixos índices de cópia, mesmo com estudantes desinteressados em fazer os deveres de casa, nos intrigou. Compreender a origem desse interesse demanda investigação aprofundada sobre o caso. Contudo, consideramos que o conceito de engajamento pode contribuir para a interpretação desse resultado. Entendemos o engajamento como sendo a relação que o estudante estabelece com uma atividade em função do contexto no qual ela se dá. Trata-se de um conceito multidimensional que abarca aspectos comportamentais, emocionais e cognitivos. Alterações no contexto de desenvolvimento de uma atividade podem levar a mudança no engajamento dos estudantes. Estudantes desmotivados ou desinteressados por uma disciplina podem se engajar em tarefas específicas da mesma (FREDRICKS; BLUMENFELD; PARIS, 2004). 
Nossa hipótese explicativa se relaciona às ações do professor e aos propósitos pedagógicos das tarefas para casa. A estreita relação das tarefas para casa com as tarefas de classe, numa perspectiva de inversão da sala de aula, ajuda os estudantes a perceberem, consciente ou inconscientemente, que as tarefas são importantes para o acompanhamento do curso de Física. Associado a isso, há as ações do professor que visam destacar essa relação entre o que deve ser feito em casa e o que será feito em sala, bem como chamar a atenção dos estudantes para a importância dos deveres para o bom desempenho em Física. Os professores também buscam, nas reuniões de coordenação de série, sintonizar ainda mais as atividades de casa e sala; e otimizar a extensão dos deveres e a sua qualidade. Dito em outras palavras, o engajamento dos estudantes é conseguido também com trabalho pedagógico nas reuniões de coordenação de série e com o convencimento contínuo dos estudantes sobre a importância dos deveres de casa no curso de Física.

Por fim, pedimos aos estudantes que avaliassem se os deveres de casa contribuíram para o aprendizado em Física. O gráfico 6 mostra que há uma grande diferença sobre essa percepção entre os estudantes de 2017 e 2019. Em 2017, cerca de 65\% dos estudantes afirmaram que os deveres contribuíram muito para que aprendessem Física, frente a 5\% dos estudantes em 2019. Os que disseram que os deveres não contribuíram com a aprendizagem foram cerca de $2 \%$, em 2017, e 35\%, em 2019.

Gráfico 6 - Avaliação da percepção dos estudantes sobre a contribuição das tarefas para casa para o aprendizado em Física.

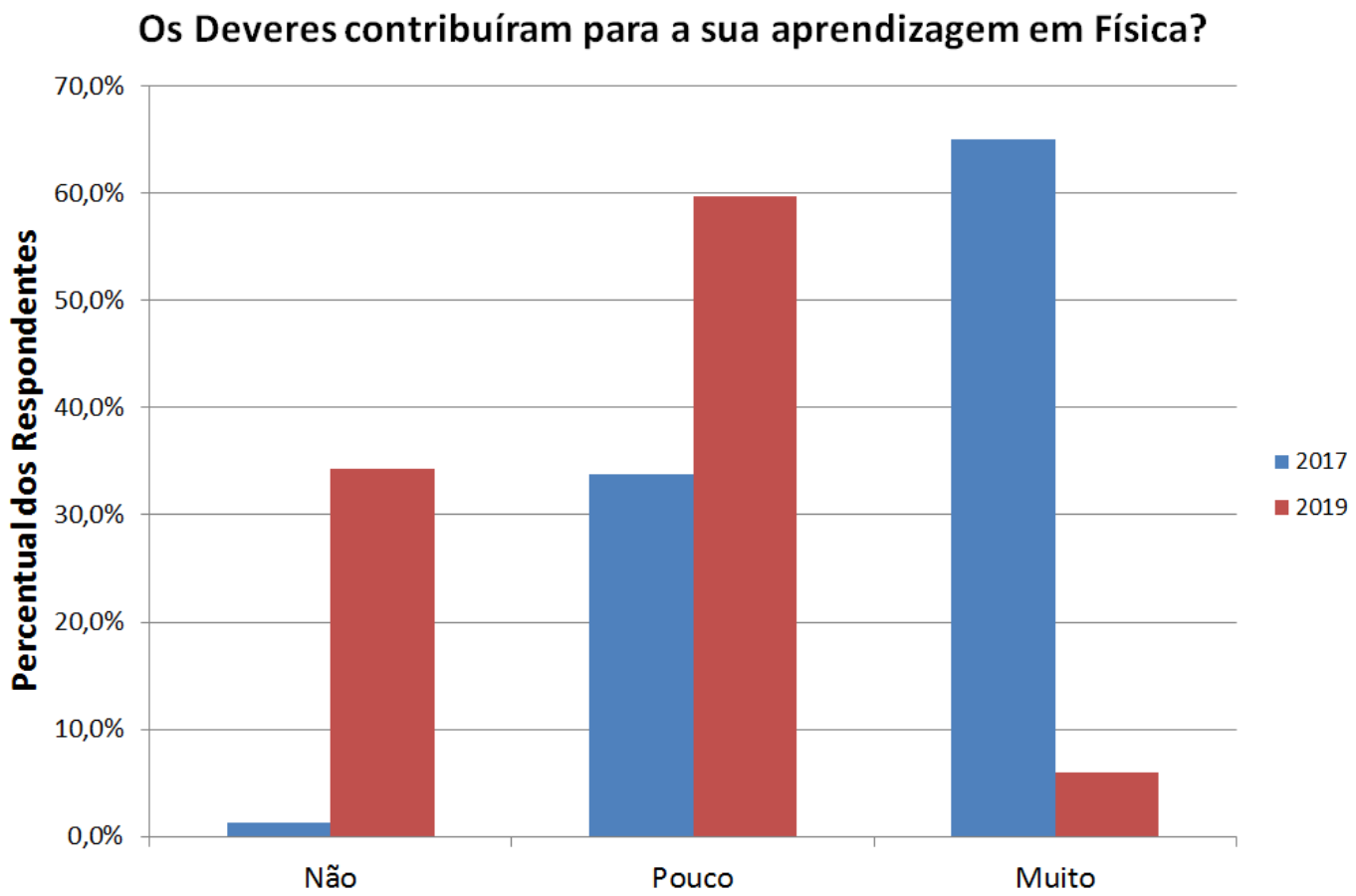

Esse resultado pode estar associado aos demais aqui apresentados. Como vimos, nos gráficos 2, 3, 4 e 5, as avaliações dos estudantes em 2017 foram melhores que as avaliações 
em 2019. O que pode ter levado a essa situação, uma vez que o curso de Física e a tarefas para casa foram praticamente os mesmos?

Essa questão não é trivial. Não temos dados e evidências suficientes para respondêla. Contudo, temos consciência de que o contexto de desenvolvimento das tarefas foi diferente em um ano e em outro.

Entendemos que, nos dois anos, os estudantes estavam desinteressados, mas mostraram-se engajados em realizar as tarefas. Contudo, em 2019, esse engajamento não foi tão expressivo quanto em 2017. O curso de Física e as tarefas para casa foram os mesmos. Contudo, as intervenções dos professores relacionadas à atribuição das tarefas para casa não foram as mesmas: o trabalho de convencimento sobre a importância das tarefas para casa para o curso de Física foi menos sistemático e esse assunto foi menos pautado nas reuniões de coordenação de série. Tal afirmação não significa que esse trabalho não tenha sido feito, mas que não foi tão ostensivo em 2019 como foi em 2017. Para que o trabalho com as tarefas para casa seja bem sucedido não basta ter um curso bem estruturado, boa equipe de professores e estudantes com potencial. É preciso cuidar dia-a-dia para que os estudantes percebam a importância e se engajem nessa atividade particular.

\section{Considerações Finais}

Foi um desafio escrever este relato. A consciência de detalhes e complexidades de nossa própria vivência quase nos paralisou. $\mathrm{O}$ receio de escrever igual à maioria dos artigos com relatos de experiência também. Porém, a maior dificuldade foi manter a coerência com nossos valores e convicções. Insistimos com o registro do que nos preocupou e do que nos moveu, por acreditar que isso pode valer a colegas que tenham disposição de arriscar e a sabedoria de agir sob inspiração de relatos de experiência docente.

Julgamos que não seria adequado dar à nossa vivência o caráter de um experimento, nem usar retórica de relato de pesquisa. As circunstâncias de uma experiência profissional docente são sempre particulares e datadas. Como então posarmos de modelo a quem quer que viesse a ler este texto? Nosso cuidado em detalhar as circunstâncias não deve ser mal entendido. Apostamos na capacidade e determinação docentes. Contudo, uma consciência transitiva ingênua (FREIRE, 1982) pode criar ilusões. Por isso, nos assombra a visão de uma leitora ou leitor que tenta nos imitar e acaba por cair em desilusão.

Descrevemos nosso perfil profissional e de nossos colegas - bem como o contexto escolar em que trabalhamos - com intuito de mostrar que condições tínhamos na ocasião. Não queremos levar alguém, amanhã, a tentar reproduzi-las. Apostamos no seu protagonismo, mas as circunstâncias que você viverá serão dadas e transmitidas pelo seu passado, não pelo nosso; pela história de outra escola, em outro tempo.

Precisávamos descrever nossas vivências juntamente com dados sobre o embasamento que tínhamos para tomar as decisões que tomamos, pois sabemos que as pessoas sempre se inspiram umas nas outras. Não assumimos a tarefa de dizer o que nos 
propiciou a fortuna de fazer nossa própria história. Tampouco, desprezamos a possibilidade de alguém enxergar nexo causal entre os resultados que relatamos aqui e nossas características ou aquelas do contexto escolar onde trabalhamos. Nosso cuidado descritivo visou deixar um alerta: podemos ter feito nossa história, mas não fizemos o que queríamos, nem nas circunstâncias que escolhemos. Fizemos o que pudemos fazer sob as circunstâncias existentes; dadas e transmitidas do passado da escola onde trabalhamos e da trajetória de cada um de nós. O mesmo se dará a quem se inspirar em nós.

Sucesso - o que quer que se considere ser isso - em grande medida é fruto do acaso. Dito de outra maneira: as chances de uma iniciativa dar errado são maiores que as dela darem o resultado planejado. Nosso relato visa ilustrar tanto essa premissa, quanto outra: a de que atividades orientadas pela pesquisa aumentam as chances de sucesso. Destacamos isso pois os dados não falam por si. Quem se ativer aos resultados sobre a percepção dos estudantes pode tirar uma conclusão distinta de alguém que atente para os resultados sobre o engajamento dos estudantes.

As consultas que fizemos às nossas turmas em 2017 e em 2019 mostram resultados coerentes entre si, mas quantitativa e qualitativamente distintos. Em um relato de pesquisa, nós não nos atreveríamos a usar essas consultas para fazer qualquer afirmação categórica. Algumas perguntas são diferentes, outras têm alternativas de resposta com redação ou escala modificada. Como tirar qualquer conclusão ao cotejar as respostas obtidas?

Fora do contexto, as respostas dos estudantes às consultas sobre suas opiniões, não nos permitiriam concluir muita coisa. Mas, como escrevemos um relato de experiência e o fizemos enquanto professores em exercício regular da docência, nós podemos legar a colegas e estudantes de licenciatura mais do que gráficos daquelas respostas e dos números de tarefas entregues nas duas séries históricas. Podemos deixar nosso depoimento.

Os resultados em 2019 não foram tão bons quanto os de 2017. Talvez tenham sido circunstâncias fora de nosso conhecimento e controle. Talvez tenha sido o efeito da longevidade do expediente de passar tarefas. Talvez tenham sido circunstâncias pessoais nossas. Talvez tenha ocorrido uma transformação estrutural da escola. Como saber? Talvez com paciência; mais do que esforço e determinação.

Nossas escolhas nos propiciaram resultados alvissareiros por um tempo longo o suficiente para descartarmos a hipótese de que o engajamento que observamos foi fruto de um mero acaso. Se 2019 foi um momento de virada ou uma singularidade episódica só o tempo dirá. Conforme o caso, talvez voltemos a enfrentar nossas dificuldades com o desafio de escrever relatos como este. É uma maneira de insistirmos na tese da importância da colaboração docente e da pesquisa em ensino.

\section{Referências}

AMALDI, U. Imagens da Física: As idéias e as experiências, do pêndulo aos quarks. São Paulo: Scipione, 1995. 
BEREITER, C.; SCARDAMALIA, M. Rethinking Learning. In: OLSON, D. R.; TORRANCE, N. (Org.). The handbook of education and human development: New models of learning, teaching, and schooling. Cambridge: Blackwell, 1996. p. 485-513.

BERGMANN, J.; SAMS, A. Flip your Classroom: Reach Every Student in Every Class Every Day. 1. ed. Washington: ISTE, 2012.

BONHAM, S. W.; DEARDORFF, D. L.; BEICHNER, R. J. Comparison of student performance using web and paper-based homework in college-level physics. Journal of Research in Science Teaching, v. 40, n. 10, p. 1050-1071, 2003.

CARVALHO, M. E. P. Escola como extensão da família ou família como extensão da escola? O dever de casa e as relações família-escola. Revista Brasileira de Educação, n. 25, p. 94$104,2004$.

CARVAlHO, M. E. P.; SERPA, M. H. B. Dever de casa: visões de mães e professoras. Olhar de Professor, v. 9, n. 1, p. 31-46, 2006.

CHENG, K. K. et al. Using an online homework system enhances students' learning of physics concepts in an introductory physics course. American Journal of Physics, v. 72, n. 11, p. 1447-1453, 2004. Disponível em: <http://aapt.scitation.org/doi/10.1119/1.1768555>.

DETTMERS, S. et al. Homework works if homework quality is high: Using multilevel modeling to predict the development of achievement in mathematics. Journal of Educational Psychology, v. 102, n. 2, p. 467-482, 2010. Disponível em:

$<$ http://doi.apa.org/getdoi.cfm?doi=10.1037/a0018453>.

DEWEY, J. Experience and Education. New York: Touchstone, 1997.

FAGEN, A. P.; CROUCH, C. H. Peer Instruction: Results from a Range of Classrooms. The Physics Teacher, v. 40, n. April, p. 206, 2002.

FARIA, A. F.; VAZ, A. M. Experiências de Pensamento Científico em Aulas de Física. Investigações em Ensino de Ciências, v. 23, n. 1, p. 266-294, 2018.

FISHER, D.; LAPP, D.; FREY, N. Homework in Secondary Classrooms: Making It Relevant and Respectful. Journal of Adolescent and Adult Literacy, v. 55, n. 1, p. 71-74, 2011. 
FREDRICKS, J. A.; BLUMENFELD, P. C.; PARIS, A. H. School Engagement: Potential of the Concept, State of the Evidence. Review of Educational Research, v. 74, n. 1, p. 59-109, 2004. Disponível em: <http://rer.sagepub.com/cgi/doi/10.3102/00346543074001059>.

FREIRE, P. Educação como Prática da Liberdade. 13. ed. Rio de Janeiro: Paz e Terra, 1982.

FREIRE, P. Pedagogia da Autonomia: Saberes necessários à prática educativa. São Paulo: Paz e Terra, 1996.

HENDERSON, C.; DANCY, M. Impact of physics education research on the teaching of introductory quantitative physics in the United States. Physical Review Special Topics Physics Education Research, v. 5, n. 2, p. 1-8, 2009.

JENSEN, J. L. et al. Investigating Strategies for Pre-Class Content Learning in a Flipped Classroom. Journal of Science Education and Technology, n. Jun, p. 1-13, 2018. Disponível em: <http://link.springer.com/10.1007/s10956-018-9740-6>.

LASRY, N.; MAZUR, E.; WATKINS, J. Peer instruction: From Harvard to the two-year college. American Journal of Physics, v. 76, n. 11, p. 1066-1069, 2008.

LENAERTS, J.; WIEME, W.; ZELE, E. VAN. Peer instruction: a case study for an introductory magnetism course. European Journal of Physics, v. 24, p. 7-14, 2003.

MAZUR, E. Peer Instruction: A User's Manual. Upper Saddle River: Prentice Hall, 1997.

MCDERMOTT, L. C. How we teach and how students learn - A mismatch? American Journal of Physics, v. 61, n. 4, p. 295-298, 1993.

MCDERMOTT, L. C.; SHAFFER, P. S. Research as a guide for curriculum development: An example from introductory electricity. Part I: Investigation of student understanding. American Journal of Physics, v. 60, n. 11, p. 994-1003, 1992. Disponível em: $<$ http://aapt.scitation.org/doi/10.1119/1.17003>.

MCDERMOTT, L. C.; SHAFFER, P. S. Tutorials in Introductory Physics. Upper Saddle River, NJ: Prentice Hall, 2002. Disponível em:

$<$ http://courses.washington.edu/uwpeg/tutorial $>$.

MESTRE, J. et al. The Effect of Web-Based Homework on Test Performance in Large 
Enrollment Introductory Physics Courses. Journal of Computers in Mathematics and Science Teaching, v. 21, n. 3, p. 229-251, 2002.

OLIVEIRA, T. E. DE; ARAUJO, I. S.; VEIT, E. A. Sala de aula invertida (flipped classroom): inovando as aulas de física. Física na Escola, v. 14, n. 2, p. 4-13, 2016.

OLSON, D. R.; BRUNER, J. S. Folk Psychology and Folk Pedagogy. In: OLSON, D. R.; TORRANCE, N. (Org.). The handbook of education and human development: New models of learning, teaching, and schooling. Cambridge: Blackwell, 1996. p. 9-27.

POZO, J. I.; GÓMEZ, M. Á. Aprender y enseñar ciencia: del conocimiento cotidiano al conocimiento científico, 1998. p. 152.

REIDSEMA, C. et al. (Org.). The flipped classroom - Practice and Practices in Higher Education. Gateway East: Springer Nature, 2007.

RESENDE, T. F. Entre escolas e famílias: revelações dos deveres de casa. Paidéia (Ribeirão Preto), v. 18, n. 40, p. 385-398, 2008.

ROSÁRIO, P. et al. Does homework design matter? The role of homework's purpose in student mathematics achievement. Contemporary Educational Psychology, v. 43, p. 10-24, 2015 .

SMITH, M. K. et al. Why peer discussion improves student performance on in-class concept questions. Science, v. 323, p. 122-124, 2009.

SUPPAPITTAYAPORN, D.; EMARAT, N.; ARAYATHANITKUL, K. The effectiveness of peer instruction and structured inquiry on conceptual understanding of force and motion: a case study from Thailand. Research in Science \& Technological Education, v. 28, n. 1, p. 63-79, 2010.

TROWBRIDGE, D. E.; MCDERMOTT, L. C. Investigation of student understanding of the concept of acceleration in one dimension. American Journal of Physics, v. 49, n. 3, p. $242-$ 253, 1981. Disponível em: <http://aapt.scitation.org/doi/10.1119/1.12525>.

VAZ, A. M.; JULIO, J. M.; FARIA, A. F. Princípios para investigação da experiência em atividades baseadas em pesquisas em Ensino de Física. In: ENCONTRO DE PESQUISA EM ENSINO DE FÍSICA, 14, 2012, Maresias. Atas... São Paulo: SBF, 2012. p. 1-9. Disponível em: <http://www.sbf1.sbfisica.org.br/eventos/epef/xiv/sys/resumos/T0069-2.pdf>.

Direito autoral e licença de uso: Este artigo está licenciado sob uma Licença Creative Commons. 